\title{
Research and Application of Multi-functional Backup Automatic Switch Based on Decoupling Theory for Substation
}

\author{
Zhiqiang $\mathrm{Gu}^{1}$, Dahai $\mathrm{Tang}^{2}$, Jing $\mathrm{Li}^{2}$, Yongming $\mathrm{Chen}^{2}$, Bin $\mathrm{Cao}^{2}$ and $\mathrm{Tian} \mathrm{Wu}^{3}$ \\ ${ }^{1}$ State Grid Wuxi Electric Power Supply Company, Jiangsu Wuxi, 214061, China \\ ${ }^{2}$ State Grid Zhenjiang Electric Power Supply Company, Jiangsu Wuxi, 212001, China \\ ${ }^{3}$ College of Electrical Engineering\& New Energy, China Three Gorges University , Hubei Yichang, 443002,China
}

\begin{abstract}
There are three kinds of main connection modes, including single bus connection, inner bridge connection and enlarged inner bridge connection, in the different stages of the construction of the internal bridge connection circuit for substation, which were equipped with one of the three backup automatic switching devices for a main connection circuit. The control logic control (decoupling control logic) composed of two inner bridge auto-restart control logic were adopted to realize the control logic expanded internal bridge connection auto-restart, by setting the control words for operation mode, and to achieve mufti-function auto-restart control logic principle schemes (two principle scheme) of primary connection circuit for expansion inner bridge, bridge and single bus connection. These adaptive functions for primary main circuit operation modes were achieved through judging the operation of gate position contact point of each circuit breaker and two position relay contact. The two kinds of decoupling principle of the multifunctional automatic switching device were developed according to these principles. Test results show that the multifunctional automatic switching devices can function adaptive for three main circuit standby automation switching and operation mode, to achieve the control logic to conduct the three main circuit automatic switching devices operation effectively, which has engineering application prospects.
\end{abstract}

Keywords-backup automatic switch; mufti-function; selfadaption; decoupling theory; overall modes of operation

\section{INTRODUCTION}

At present, expanded inner bridge circuit once is the main circuit mode used for $110 \mathrm{kV}$ and $220 \mathrm{kV}$ substation in China. At the early stage of substation construction, in order to save investment cost, 4 circuit breakers are not used completely, only 2 or 3 circuit breakers are installed. Based on this condition, reserve power automatic connection device [1 11] (backup automatic switch for short) with single bus connection and inner bridge connection are constructed and put into operation. However, traditional expanded internal bridge backup automatic switch was only equipped with 1 circuit breaker backup with 4 operation modes and operational logic was too simple. Expanded inner bridge backup automatic switch in the market has been operated in the modes of 2 circuit breakers backup and 3 circuit breakers backup. There were at least 9 common operation modes [5 6]. When the operation modes of backup automatic switch were insufficient, the substation operation modes were limited, thereby reducing the reliability of power supply of the substation. On the other hand, one set of expanded inner bridge backup automatic switch cannot meet the operation requirements of the main connection modes of a substation above. When the above primary main circuits are refreshed, corresponding backup automatic switching devices are required to be changed according to different primary main circuits, so as to adapt demands in reconstruction of primary main circuit. Meanwhile, backup automatic switching devices can continue to operate after redesigning and reconnecting cables, which greatly increases investment cost and construction cycles, manpower and material resources, and reduces the reliability of power supply. Inner bridge backup automatic switch logic principles of standby power circuit breaker charging was used in literature [12] while that of power supply circuit breaker charging was applied in literature [13]. These two inner bridge backup automatic switches satisfied 6 operation modes of the above inner bridge backup automatic switch. Therefore, multifunctional backup automatic switch decoupling control logic were achieved by applying 2 control logic principles of literature [12] or literature [13] or one principle of literature [12] and 1 inner bridge backup automatic switch logic of literature [13] (or other inner bridge backup automatic switch logic), and self-adaption of backup automatic switch functions of single bus connection, inner bridge connection and expanded inner bridge connection can be realized. In this paper, two inner bridge backup automatic switch logic were used, to achieve multifunctional backup automatic switch decoupling control logic. In consequences, it was very necessary to develop a multifunctional backup automatic switching device that can adapt multiple main connection modes and self adapt all modes of operation of backup automatic switch under the above main connection. The multifunctional backup automatic switching devices were developed, for which one control logic backup automatic switch composed of two control logic of inner bridge backup automatic switches with same principles (decoupling control logic) was used in this backup automatic switching device, to realize the control logic of expanded inner bridge connection backup automatic switch. Multi-function backup automatic switch control logic principle scheme to expanded inner bridge, inner bridge connection and single bus connection and other different primary connection circuits (two principle schemes) were achieved and adapted by setting the control words for operation modes and the self-adaptive functions for the primary main circuit operation mode were achieved 
through judging the operation of gate position contact condition and two position relay contact KKJ of each circuit breaker. According to the above principle, two kinds of decoupling principle of the multifunctional automatic switching device were developed.

\section{Change in Main Circuit of Substation And Backup Automatic Switching Device}

In the early stage of new substation construction, in order to save investment cost, 4 circuit breakers generally were not installed completely, but only 2 or 3 circuit breakers were used. Based on this, there were three kinds of main connection modes, including single bus connection, inner bridge connection and expanded inner bridge connection. 1) If only 2 circuit breakers were equipped, primary main connection of the substation were changed into single bus connection, as shown in Figure I. 2) If 4 circuit breakers were equipped, primary main connection of the substation were changed into expanded inner bridge connection. If dual power supply was adopted, primary main connection was as shown in Figure II. 3) If only 3 circuit breakers were equipped, primary main connection of the substation were changed into inner bridge connection, as shown in Figure III. In addition, main connection backup automatic switching devices matching with backup automatic switches of three type main connections need to be equipped in the different stages of the construction of expanded inner bridge connection substation. What's more, three backup automatic switching devices can operate after reconnecting cables.

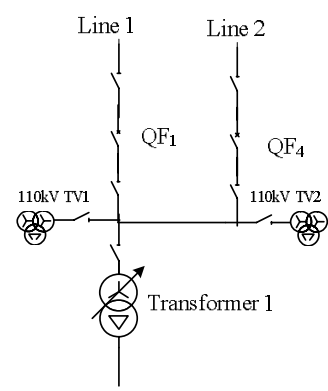

FIGURE I. SINGLE BUS MAIN CIRCUIT

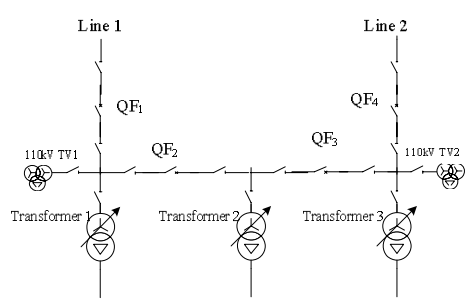

FIGURE II. EXPANDING INNER BRIDGE MAIN CIRCUIT

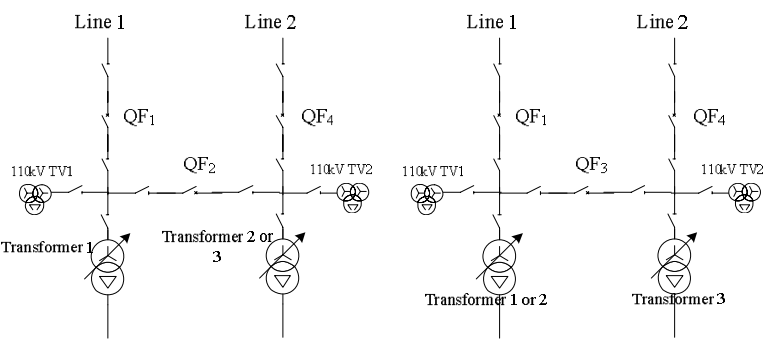

(1) First inner bridge circuit (2) Second inner bridge circuit FIGURE III. INNER BRIDGE MAIN CIRCUIT

\section{DECOUPLING CONTROL PRINCIPLE OF Multifunctional BaCKup AutOMATIC Switch AND REALIZATION}

Complex primary main circuit backup automatic switching devices such as expanded inner bridge connection backup automatic switch and pentagon connection backup automatic switch have the following characteristics: many operation modes, which is difficult to memorize the complex control modes. Decoupling control theory of backup automatic switch means that one complex primary main connection backup automatic switching device was simplified into two or several common simple primary main connection backup automatic switching devices, as well as two or several common simple primary main connection backup automatic switch control logic, which operate and constitute the device together. Common simple primary main connection backup automatic switches include dual power supply single bus connection backup automatic switch and dual power supply inner bridge connection backup automatic switch, etc.

A. Simplification of Expanded Inner Bridge Connection and Backup Automatic Switch Decoupling Control Principles

- Simplification of expanded inner bridge connection

Because any dual power supplies cannot operate in parallel for long time, at least one of circuit breakers in the loop between every dual power supplies shall be in hot-standby state. Therefore, "exhaustive" expanded inner bridge connection backup automatic switch had 12 operation modes (as shown in TABLE I), including 9 common-used operation modes [2 3].

As can be known from literature [2], expanded inner bridge primary main connection was composed of two inner bridge connections, as shown in TABLE I:

a. Circuit breakers QF1, QF2 and QF4 constitute the first dual-power-supply inner bridge connection, as shown in Figure 2 (1). Operation of main transformer 1, 2 or 3 was controlled by $\mathrm{QF} 1, \mathrm{QF} 2$ and QF4 of which QF2 is bridge circuit breaker.

b. Circuit breakers QF1, QF3 and QF4 constitute the second dual-power-supply inner bridge connection, as shown in Figure 2 . Operation of main transformer 1,2 or 3 was controlled by QF1, QF3 and QF4 of which QF3 was bridge circuit breaker.

- Decoupling control theory of expanded inner bridge connection backup automatic switch

For the same reason, the dual power supply expanded inner bridge connection backup automatic switch control logic also 
can be made up of 2 inner bridge connection backup automatic switches (decoupling method[4 5], decoupling expanded inner bridge backup automatic switch for short):

a. The first inner bridge connection backup automatic switch 1 with dual power supply was made up of 3 circuit breakers: QF1, QF2 and QF3 (backup automatic switch 1 for short).

b. The second inner bridge connection backup automatic switch 2 with dual power supply was made up of 3 circuit breakers: QF1, QF3, QF4 (backup automatic switch 2 for short).
The relationship between expanded inner bridge backup automatic switch and backup automatic switch 1 and 2 and eleven operation mode $(\mathrm{OM})$ was formed:

OM1: completed by backup automatic switch 1 or 2 ;

OM2: completed by backup automatic switch 2;

OM 3: completed by backup automatic switch 1;

OM 4: completed by backup automatic switch 1 or 2 ;

OM 5: completed by backup automatic switch 2;

OM 6: completed by backup automatic switch 1 and 2;

TABLE I. THE OPERATION MODES OF BACKUP AUTOMATIC SWITCH IN EXPANDING INNER BRIDGE MAIN CIRCUIT

\begin{tabular}{|c|c|c|c|}
\hline Mode & Operation of CB & Hot-standby CB & Action process \\
\hline 1 & $\mathrm{QF}_{1}, \mathrm{QF}_{2}, \mathrm{QF}_{3}$ & $\mathrm{QF}_{4}$ & When power loss in incoming line 1, tripping $\mathrm{QF}_{1}$ and switching on $\mathrm{QF}_{4}$ \\
\hline 2 & $\mathrm{QF}_{1}, \mathrm{QF}_{2}, \mathrm{QF}_{4}$ & $\mathrm{QF}_{3}$ & $\begin{array}{l}\text { When power loss in incoming line 1, tripping } \mathrm{QF}_{1} \text { and switching on } \mathrm{QF}_{4} \text {; When there is power } \\
\text { loss in incoming line 2, tripping } \mathrm{QF}_{4} \text { and switching onQF }\end{array}$ \\
\hline 3 & $\mathrm{QF}_{1}, \mathrm{QF}_{3}, \mathrm{QF}_{4}$ & $\mathrm{QF}_{2}$ & $\begin{array}{l}\text { When power loss in incoming line } 1 \text {, tripping of } \mathrm{QF}_{1} \text { and switching on } \mathrm{QF}_{2} \text {; When there is } \\
\text { power LOSS in incoming line 2, tripping } \mathrm{QF}_{4} \text { and switching on } \mathrm{QF}_{2}\end{array}$ \\
\hline 4 & $\mathrm{QF}_{2}, \mathrm{QF}_{3}, \mathrm{QF}_{4}$ & $\mathrm{QF}_{1}$ & When power loss in incoming line 2, tripping $\mathrm{QF}_{4}$ and switching on $\mathrm{QF}_{1}$ \\
\hline 5 & $\mathrm{QF}_{1}, \mathrm{QF}_{2}$ & $\mathrm{QF}_{3}, \mathrm{QF}_{4}$ & When power loss in incoming line 1, tripping $\mathrm{QF}_{1}$ circuit breaker and switching onQF $\mathrm{F}_{3}$ and $\mathrm{QF}_{4}$ \\
\hline 6 & $\mathrm{QF}_{1}, \mathrm{QF}_{4}$ & $\mathrm{QF}_{2}, \mathrm{QF}_{3}$ & $\begin{array}{l}\text { When power loss in incoming line 1, tripping } \mathrm{QF}_{1} \text { circuit breaker and switching on } \mathrm{QF}_{2} \text { and } \\
\mathrm{QF}_{3} \text {; When there loss in incoming line 2, tripping } \mathrm{QF}_{4} \text { and switching onQF } \mathrm{F}_{2} \text { and } \mathrm{QF}_{3}\end{array}$ \\
\hline 7 & $\mathrm{QF}_{3}, \mathrm{QF}_{4}$ & $\mathrm{QF}_{1}, \mathrm{QF}_{2}$ & When power loss in incoming line 2, tripping $\mathrm{QF}_{4}$ and switching on $\mathrm{QF}_{1}$ and $\mathrm{QF}_{2}$ \\
\hline 9 & $\mathrm{QF}_{2}, \mathrm{QF}_{4}$ & $\mathrm{QF}_{1}, \mathrm{QF}_{3}$ & When power loss in incoming line 2, tripping $\mathrm{QF}_{4}$ and switching on $\mathrm{QF}_{1}$ and $\mathrm{QF}_{3}$ \\
\hline 10 & $\mathrm{QF}_{1}$ & $\mathrm{QF}_{2}, \mathrm{QF}_{3}, \mathrm{QF}_{4}$ & When power loss in incoming line 1, tripping $\mathrm{QF}_{1}$ and switching on $\mathrm{QF}_{2}$ and $\mathrm{QF}_{3}$ \\
\hline 11 & $\mathrm{QF}_{4}$ & $\mathrm{QF}_{1}, \mathrm{QF}_{2}, \mathrm{QF}_{3}$ & When power loss in incoming line 2, tripping $\mathrm{QF}_{4}$ and switching on $\mathrm{QF}_{1}$ and $\mathrm{QF}_{2}$ \\
\hline
\end{tabular}

Note: no matter what main transformer 1, 2 or 3 of the substation run or stopped, corresponding backup automatic switching devices don' t operate, which was stopping mode. Modes 8 and 9 were not commonly used.

OM7: completed by backup automatic switch 1;

OM 8: completed by backup automatic switch 1;

OM 9: completed by backup automatic switch 2;

OM 10: completed by backup automatic switch 1 and 2;

OM 11: completed by backup automatic switch 1 and 2;

- Analysis of decoupling control theory of expanded inner bridge connection backup automatic switch

The circuit breakers operation states of QF1, QF2, QF3 and QF4 were represented as A, B, C and D separately and logic algebra were expressed as 1 separately, as shown in Figure III. $\overline{\mathrm{A}}, \overline{\mathrm{B}}, \overline{\mathrm{C}}$ and $\overline{\mathrm{D}}$ are used to represent nonoperation state of the circuit breakers QF1, QF2, QF3 and QF4, i.e. hot stand-by duty, and logic algebra was expressed as 0 separately.

A) Mathematical models of inner bridge backup automatic switch 1 and 2
Inner bridge connection backup automatic switch 1 and 2 had 6 operation modes separately (take backup automatic switch 1 for example: a. operating circuit breaker QF1, QF4; backup switching circuit breaker QF2; b. operating circuit breaker QF1, QF2; backup switching circuit breaker QF4; c. operating circuit breaker QF4, QF2; backup switching circuit breaker QF1; d. operating circuit breaker QF1; backup switching circuit breaker QF4, QF2; e. operating circuit breaker QF4; backup switching circuit breaker QF1, QF2; f. stopping mode. For backup automatic switch 2, QF2 was replaced with QF3), the mathematical models or logic algebra expressions of them were expressed as expressions (1) and (2) separately.

$$
\begin{aligned}
& A \bar{B} D+A B \bar{D}+\bar{A} B D+A \bar{B} \bar{D}+\overline{A B} D+\overline{A B \bar{B}} \\
& A \bar{C} D+A C \bar{D}+\bar{A} C D+A \bar{C} \bar{D}+\overline{A C} D+\overline{A C} \bar{D}
\end{aligned}
$$

B) Theory testing of " decoupling method" of expanded inner bridge connection backup automatic switch 
In the operation, inner bridge backup automatic switches 1 and 2 shall synthesize with each other, to complete the logic of expanded inner bridge connection backup automatic switch. Logically, the logical relationship between them shall be "or". Hence, there were logic algebra expressions of expanded inner bridge connection backup automatic switching operation mode.

$$
\begin{aligned}
& (\mathrm{A} \overline{\mathrm{B}} \mathrm{D}+\mathrm{AB} \overline{\mathrm{D}}+\overline{\mathrm{A}} \mathrm{BD}+\mathrm{A} \overline{\mathrm{BD}}+\overline{\mathrm{AB}} \mathrm{D}+\overline{\mathrm{AB}} \overline{\mathrm{D}}) \\
& +(\mathrm{A} \overline{\mathrm{C}} \mathrm{D}+\mathrm{AC} \overline{\mathrm{D}}+\overline{\mathrm{A}} \mathrm{CD}+\mathrm{A} \overline{\mathrm{CD}}+\overline{\mathrm{AC}} \mathrm{D}+\overline{\mathrm{ACD}})
\end{aligned}
$$

Considering that logic algebra had identical equations $\mathrm{C}+\overline{\mathrm{C}}=1$ and $\mathrm{B}+\overline{\mathrm{B}}=1$. Hence, the logic algebra expression of expanded inner bridge connection backup automatic switching operation mode after simplification turned to the expression (4):

$$
\begin{aligned}
& (A \overline{\mathrm{B}} D+A B \overline{\mathrm{D}}+\overline{\mathrm{A}} B D+A \overline{\mathrm{B}} \overline{\mathrm{D}}+\overline{\mathrm{AB}} D+\overline{\mathrm{AB}} \overline{\mathrm{D}}) \\
& +(A \overline{\mathrm{C}} D+A C \overline{\mathrm{D}}+\overline{\mathrm{A}} C D+A \overline{\mathrm{C}} \overline{\mathrm{D}}+\overline{\mathrm{AC}} D+\overline{\mathrm{AC}} \overline{\mathrm{D}}) \\
& =(A \overline{\mathrm{B}} D+A B \overline{\mathrm{D}}+\overline{\mathrm{A}} B D+A \overline{\mathrm{BD}}+\overline{\mathrm{AB}} D+\overline{\mathrm{AB}} \overline{\mathrm{D}}) \\
& *(C+\overline{\mathrm{C}})+(A \overline{\mathrm{C}} D+A C \overline{\mathrm{D}}+\overline{\mathrm{A}} C D+A \overline{\mathrm{C}} \overline{\mathrm{D}}+\overline{\mathrm{AC}} D \\
& +\overline{\mathrm{AC}} \overline{\mathrm{D}}) *(B+\overline{\mathrm{B}})
\end{aligned}
$$

Calculating expression (4) and settling it, then the logic algebra expression of expanded inner bridge connection backup automatic switching operation mode turned to the expression(5) after simplification:

$$
\begin{aligned}
& (\mathrm{A} \overline{\mathrm{B}} \mathrm{D}+\mathrm{AB} \overline{\mathrm{D}}+\overline{\mathrm{A}} \mathrm{BD}+\mathrm{A} \overline{\mathrm{BD}}+\overline{\mathrm{AB}} \mathrm{D}+\overline{\mathrm{ABD}}) \\
& +(\mathrm{A} \overline{\mathrm{C}} \mathrm{D}+\mathrm{AC} \overline{\mathrm{D}}+\overline{\mathrm{A}} \mathrm{CD}+\mathrm{A} \overline{\mathrm{C}} \overline{\mathrm{D}}+\overline{\mathrm{AC}} \mathrm{D}+\overline{\mathrm{AC}} \overline{\mathrm{D}}) \\
& =\mathrm{A} \overline{\mathrm{B}} \mathrm{CD}+\mathrm{ABC} \overline{\mathrm{D}}+\overline{\mathrm{A}} \mathrm{BCD}+\mathrm{AB} \overline{\mathrm{C}} \mathrm{D}+\overline{\mathrm{AB}} \mathrm{CD} \\
& +\mathrm{A} \overline{\mathrm{B}} \overline{\mathrm{C}} \mathrm{D}+\mathrm{AB} \overline{\mathrm{C}} \overline{\mathrm{D}}+\mathrm{A} \overline{\mathrm{B}} \mathrm{C} \overline{\mathrm{D}}+\overline{\mathrm{A}} \overline{\mathrm{C}} \mathrm{D}+\mathrm{A} \overline{\mathrm{B}} \overline{\mathrm{C}} \overline{\mathrm{D}} \\
& +\overline{\mathrm{A}} \overline{\mathrm{B}} \overline{\mathrm{C}} \mathrm{D}+(\overline{\mathrm{A}} \mathrm{B} \overline{\mathrm{C}} \overline{\mathrm{D}}+\overline{\mathrm{AB}} \overline{\mathrm{B}} \overline{\mathrm{D}}+\overline{\mathrm{A}} \overline{\mathrm{B}} \overline{\mathrm{C}} \overline{\mathrm{D}})
\end{aligned}
$$

Every logic algebra expression of one field in expression (5) represents one operation mode of this backup automatic switch, the calculating result of logic algebra expression (5) shows that there were 14 operation modes of this expanded inner bridge connection backup automatic switch apparently. But these two operation modes of and are equal to stopping modes of inner bridge connection 1 and 2 separately, they were also stopping modes in principle; therefore, there were 12 operation modes of expanded inner bridge connection backup automatic switch in theory, hence the logic algebra expression of expanded inner bridge connection backup automatic switching operation mode after simplified turns to the expression (6), i.e., according to the theoretical analysis, there were 12 operation modes of expanded inner bridge connection backup automatic switch.

$$
\begin{aligned}
& (\mathrm{A} \overline{\mathrm{B}} \mathrm{D}+\mathrm{AB} \overline{\mathrm{D}}+\overline{\mathrm{A}} \mathrm{BD}+\mathrm{A} \overline{\mathrm{BD}}+\overline{\mathrm{AB}} \mathrm{D}+\overline{\mathrm{ABD}}) \\
& +(\mathrm{A} \overline{\mathrm{C}} \mathrm{D}+\mathrm{AC} \overline{\mathrm{D}}+\overline{\mathrm{A}} \mathrm{CD}+\mathrm{A} \overline{\mathrm{C}} \overline{\mathrm{D}}+\overline{\mathrm{AC}} \mathrm{D}+\overline{\mathrm{AC}} \overline{\mathrm{D}}) \\
& =\mathrm{A} \overline{\mathrm{B}} \mathrm{CD}+\mathrm{ABC} \overline{\mathrm{D}}+\overline{\mathrm{A}} \mathrm{BCD}+\mathrm{AB} \overline{\mathrm{C}} \mathrm{D}+\overline{\mathrm{AB}} \mathrm{CD} \\
& +\mathrm{A} \overline{\mathrm{B}} \overline{\mathrm{C}} \mathrm{D}+\mathrm{AB} \overline{\mathrm{C}} \overline{\mathrm{D}}+\mathrm{A} \overline{\mathrm{B}} \mathrm{C} \overline{\mathrm{D}}+\overline{\mathrm{A}} \mathrm{B} \overline{\mathrm{C}} \mathrm{D}+\mathrm{A} \overline{\mathrm{B}} \overline{\mathrm{C}} \overline{\mathrm{D}} \\
& +\overline{\mathrm{A}} \overline{\mathrm{B}} \overline{\mathrm{C}} \mathrm{D}+\overline{\mathrm{A}} \overline{\mathrm{B}} \overline{\mathrm{C}} \overline{\mathrm{D}}
\end{aligned}
$$

The operation modes of and in expression (6) also existed in practical operation. For example, building QF2 or QF3 had not been taken into consideration when the substation was built (at this time, the circuit breaker was always in operation position. This expanded inner bridge connection is equal to inner bridge connection and two operation modes of and were equal to the operation mode of inner bridge connection 1 or 2). Or when a new expanded inner bridge connection backup automatic switch on the substation was installed, the related quantity of circuit breaker QF2 or QF3 can be placed at the operating position generally and expanded inner bridge connection backup automatic switch was turned into inner bridge connection backup automatic switch because only 2 transformers were new installed. Therefore, these 2 operation modes of and appeared in perfect expanded inner bridge connection backup automatic switch rarely.

\section{C) Comparison of operation modes}

Compared with TABLE I, the operation mode of "exhaustive" expanded inner bridge connection backup automatic switch was consistent with the operation mode of simplifying expanded inner bridge connection backup automatic switch in the calculating result of logic algebra expression (6), which validated and proved that the operation mode of simplifying expanded inner bridge connection backup automatic switch was consistent with the operation mode of "exhaustive" expanded inner bridge connection backup automatic switch.

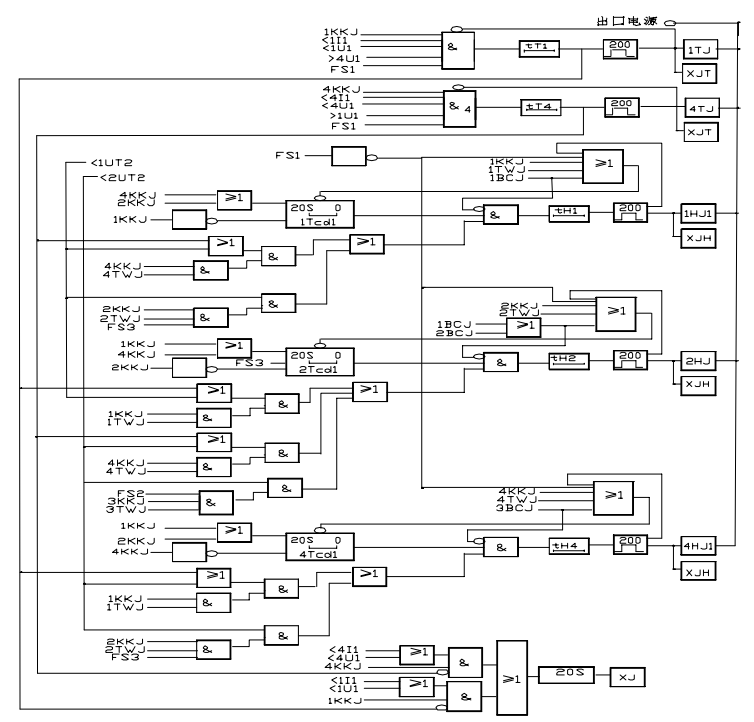

FIGURE IV. OVERALL LOGIC DIAGRAM OF MULTI-FUNCTIONAL BACKUP AUTOMATIC SWITCH FOR SWICH1 (THE LOGIC DIAGRAM OF SWITCH2 IS SIMILAR TO THAT OF SWITCH 1)

\section{B. Implementation of Decoupling Control Principles of Multifunctional Backup Automatic Switch}

- Implementation of expanded inner bridge connection backup automatic switch

When four circuit breakers on high-voltage side in the substation were equipped and main connection was expanded inner bridge connection, backup automatic switch principles can be realized by decoupling method. 
- Implementation of inner bridge connection backup automatic switch

When only 3 circuit breakers on high-voltage side in the substation were equipped, main connection was inner bridge connection. Inner bridge backup automatic switch was realized based on the above decoupling expanded inner bridge backup automatic switch. Only backup automatic switch 1 or 2 was applied. Specific method was that "operation mode of control words FS1" or "FS2" was applied, and this control word was set as " 0 ", backup automatic switch 1 or 2 was stopped (on the contrary, enabled), as shown in Figure IV.

- Implementation of single bus connection backup automatic switch

When the high-voltage side of substation was equipped with two circuit breakers, the primary connection was single bus connection. Based on decoupling of expanding inner bridge backup automatic switch only starting backup automatic switch 1 or 2 , single bus connection backup automatic switch was realized by using "operation mode of control word FS3" or "operation mode of control word FS4". The specific method was when setting the control word as " 0 ", the logic circuits related with QF2 within backup automatic switch 1 shall be hidden (or hiding the logic circuits related with QF3 within backup automatic switch 2), i.e., the circuit breaker was in the state after closing, as shown in Figure IV.

- Implementation of multi-functional backup automatic switch theory

Through the cooperation of decoupling expanded inner bridge backup automatic switch and operation modes of control word, one control logic can be used to implement the functions of multi-functional backup automatic switch of single bus connection, inner bridge and enlarged inner bridge connection backup automatic switch and all operation modes of connection backup automatic switch can be implemented automatically. When FS1, FS2, FS3 and FS4 control words for operation modes were set as 1, there was the expanded inner bridge backup automatic switch; when FS1 and FS3 control words for operation modes were set as 1 while FS2 and FS34 were set as 0 (or FS2 and FS4 control words for operation modes were set to 1 while FS1 and FS3 are set as 0), there was the inner bridge connection backup automatic switch; when FS1 control word for operation modes was set as 1 while FS2, FS3 and FS4 were set as 0 (or FS2 control word for operation mode was set as 1 while FS1, FS3 and FS4 were set as 0), there was the single bus connection backup automatic switch.

\section{Decoupling Control Scheme of Multi- FUNCTIONAL BACKUP AUTOMATIC SWITCH}

\section{A. Overall Logic Principle for Multi-functional Backup Automatic Switch}

When two inner bridge connection backup automatic switches satisfied the standard of six operation modes, the two inner bridge connection backup automatic switch devices can constitute a mufti-functional backup automatic switch device, with expanded inner bridge connection as the basic connection or two inner bridge connection backup automatic switch logic principles can constitute a decoupling control logic of mufti- functional backup automatic switch, with expanded inner bridge connection as the basic connection. The block diagram of decoupling control logic for mufti-functional backup automatic switch was shown in Figure IV.

\section{B. Self-adapting Scheme for the Operation Mode of mufti- functional Backup Automatic Switch}

Through judging the status of two position relay contact KKJ, the position relay contact TWJ or gate auxiliary contact in three circuit breakers controlled by backup automatic switch 1 or 2 in closing or open position, corresponding charging circuits can automatically be charged or discharged, to achieve the operation mode of self-adapting mufti-functional backup automatic switch. i.e., at least one circuit breaker in the three circuit breakers controlled by backup automatic switch 1 or 2 shall be supply power circuit breaker in closing; at the same time, when at least one circuit breaker was the auxiliarysupply circuit breaker in opening position of hot backup, charging circuits of corresponding circuit breaker can be charged. When all the three circuit breakers were in opening or closing status, all charging circuits shall immediately discharge, as shown in Figure IV.

\section{Starting Tripping Scheme of Mufti-functional Backup Automatic Switch}

The purpose of scheme of starting tripping muftifunctional backup automatic switch was to check whether the status of supply side circuit breaker was in the status after closing, there was "non-voltage" in supply side bus voltage, "non-current" in incoming line circuit breaker current and voltage in standby power supply circuit side. The tripping of supply power circuit breaker appeared after necessary delay, as shown in Figure IV.

\section{Charging Scheme of Mufti-functional Backup Automatic Switch}

Two control strategies of "the decoupling method of muftifunctional backup automatic switch devices" had been proposed. Two charging methods of supply power or backup power circuit breaker start were used for backup automatic switch closing charging, to ensure the backup automatic switch device operate once [4 11], thus improving the performance of backup automatic switch. Meanwhile, functions of non-voltage and synchronism check of backup automatic switch were easily implemented, small power supply was connected into the substation.

In Figure IV, tT1 and tT4 were tripping delays of QF1 and QF4 respectively, $\mathrm{tH} 1 \sim \mathrm{tH} 4$ were closing delays of $\mathrm{QF} 1 \sim \mathrm{QF} 4$ respectively, 1TJ 4TJ were tripping exit relays of QF1 QF4 respectively, $1 \mathrm{HJ} \sim 4 \mathrm{HJ}$ were closing exit relays of QF1 QF4 respectively, XJT, XJH and XJ were signal alarms and 1 4Tcd were QF1 QF4 charging circuits.

\section{E. Closing Start Scheme of mufti-functional Backup Automatic Switch}

Two start schemes were used for closing start scheme of mufti-functional backup automatic switch, i.e., "start owing to inconsistency of circuit breaker position" and "start closing while starting tripping of backup automatic switch", as shown in Figure IV. The start scheme of "start owing to inconsistency of circuit breaker position" meant that division of status two 
position relay contact KKJ of power supply circuit breaker was position after closing but position contact or position relay contact of the circuit breaker was at opening position, i.e., to start closing circuit of corresponding back-up circuit breaker when circuit breaker position of power supply was inconsistent. The scheme of "starting closing circuit while starting tripping of backup automatic switch" meant that power supply of mufti-functional backup automatic switch was in power loss state, tripping of power supply circuit breaker QF1 or QF4 was started while starting closing circuit of backup circuit breaker. , "Start owing to inconsistency of circuit breaker" applied in closing start scheme of muftifunctional backup automatic switch had the advantages of clear, simple and reliable action criterion. It can also correct non-fault-trip of circuit breaker and needs no special correcting circuit for preventing non-fault-trip of circuit breaker, thus solving the problem of non-fault-trip of all circuit breaker, particularly that of bridge circuit breaker.

\section{F. Protection Lock Scheme of mufti-functional Backup Automatic Switch}

The scheme of "consistent lock" was used for the transformer protection action lock backup automatic switch [7 8], i.e., the closing circuit of protection action blocking circuit breakers QF1 and QF2 of transformer 1; the closing circuit of protection action blocking QF2 and QF3 circuit breakers of transformer 2 and the closing circuit of protection action blocking circuit breakers QF3 and QF4 of transformer 3 The detailed measures were: a certain transformer protection action immediately discharges the charging circuit of corresponding circuit breaker of backup automatic switch, making it block and fail to action closing. The advantages were: when high-voltage side of one transformer broke down, the corresponding circuit breaker on high-voltage side of faulty transformer blocked action of backup automatic switch caused by failure equipment due to applying protection corresponding blocking scheme and will not automatically switch on failure equipment, thus avoiding expanding failure.

\section{G. Scheme of Non-voltage Check Lock Closing Circuit of mufti-functional Backup Automatic Switch}

The scheme of "consistent lock" was applied in nonvoltage check lock closing circuit of mufti-functional backup automatic switch, i.e., to apply "consistent" bus that loses power supply to "non-voltage check". To prevent nonsynchronization closing of small power source connected to backup automatic switch in substation, there were two schemes: a. the scheme of checking non-voltage of bus with power loss before backup automatic switch started closing; $b$. the scheme of double tripping the lines circuit breaker of small power supplied merged into power grid in this substation while backup automatic switch tripping. When applying the scheme of double tripping the line circuit breaker of small power supply merged into power grid, it was impossible to double trip owing to too many potential small power supply lines in substation and the loads of double-tripping circuit may be lost. Non-voltage check blocking closing circuit can avoid the above problems, but high-voltage side of corresponding transformer needed to be equipped with transformer of voltage (TV for short).

\section{H. Hardware Platform of mufti-functional Backup Automatic} Switch

Modular hardware design conception was used for hardware platform of mufti-functional backup automatic switch which contained alternating current input module (AI module), direct-current power module (PWR module), central processing unit module (CPU module), human-machine interface module (HMI module), processing circuit module (AWI module) and bursting out module (BO module) according to the classification of functional module. The central processing unit module (CPU) exchanged data with other module through inner bus. The functional module structure diagram of hardware was shown in Figure V.

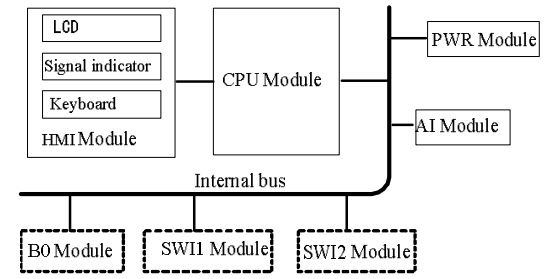

FIGURE V. STRUCTURE DIAGRAM OF FUNCTIONAL MODULE

\section{Access Volume of mufti-functional Backup Automatic Switch}

Necessary access information of mufti-functional backup automatic switch included alternating quantity information and switching value information.

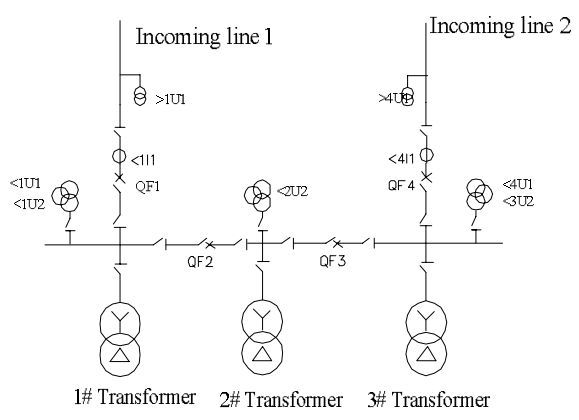

FIGURE VI. DIAGRAM OF AC INPUT OF MUFTI-FUNCTIONAL BACKUP AUTOMATIC SWITCH

Alternating quantity information included the following content as shown in Figure IV and Figure VI:

1) Bus voltage: the bus voltage of high-voltage side of transformer 1 3 (when there was no TV at bus side, switch and introduced TV through contact, for example breaker position, to apply circuit voltage):

Tripping for non-voltage check voltage: $1 \mathrm{U} 1,4 \mathrm{U} 1$;

Closing for non-voltage check voltage: 1U2, 2U2, 3U2;

2) Incoming line voltage: the voltage of incoming lines 1 and 2: 1U1, 4U1; non-line voltage transformer was allowed to not being connected;

3) Incoming line current: the current of incoming lines 1 and 2: 1I1, 4I1; 
4) Current of bridge circuit breaker: the current of two inner bridge circuit breakers.

Switching value included the following contents, as shown in Figure 4:

1) Each circuit breaker tripping position contact TWJ: tripping position contacted $1 \mathrm{TWJ} \sim 4 \mathrm{TWJ}$ of circuit breakers QF1, QF2, QF3 and QF4;

2) Each circuit breaker closing position contract KKJ: closing position contacts $1 \mathrm{KKJ} \sim 4 \mathrm{KKJ}$ of circuit breakers QF1, QF2, QF3 and QF4

3) Protection action contact BCJ: numbers 1 3 transformer protection action contacts $1 \mathrm{BCJ} \sim 3 \mathrm{BCJ}$;

4) Other switching value contacts: device maintenance switch, signal reset switch, automatic switch total switch blocking, switch blocking backup automatic switch 1 and switch blocking backup automatic switch 2 .

\section{J. Application of Multifunctional Backup Automatic Switch}

In January 2012, two multifunctional backup automatic switching devices developed by double decoupling control logic were installed in $110 \mathrm{kV}$ substation in southern suburbs of Zhenjiang Power Grid for trial operation, and the devices operate normally. $110 \mathrm{kV}$ substation in southern suburbs was complete expanded inner bridge connection, and the overall tests were conducted according to 9 common operation modes on site. Test results showed that multifunctional backup automatic switching devices of 2 principles can satisfy operation logic requirements of 9 operation modes, achieving operation effects of 3 main connection backup automatic switches completed by 1 control logic. In addition, the devices had strong adaptability and saved secondary equipment investment.

\section{CONCLUSION}

This paper put forwards 2 decoupling multifunctional backup automatic switch control logic principles and develops 2 decoupling multifunctional backup automatic switching devices which conform to basic principles of backup automatic switch with simple access information and strong self-adaption. One control logic device can meet functional requirements on backup automatic switch of single bus connection, inner bridge connection and expanded inner bridge connection in different stages of construction cycles of expanded inner bridge connection substation, and has good engineering application value.

\section{REFERENCES}

[1] Li Ming, Li Jingqiang. A wide area standby power supply automatic switching scheme based on smart grid[J]. Power System Protection and Control, 2013, 41(11): 131-133.

[2] Zhang Feng, Guo Bi-yuan. The problem existing in automatic close-up device of stand-by power supply used in sectionalized single bus scheme and its solving measures[J]. Power System Protection and Control, 2011, 39(7):133-135, 141.

[3] Liang Xinyu, Li Wei, Zhang Zhe, et al..Automatic bus transfer based on substation area information [J]. Power System Protection and Control,2016, 44(20):50-55.
[4] Tang Da-hai. Control strategy of automatic bus transfer equipment with pentagonal circuit and dual sources $[\mathrm{J}]$. Electric Power Automation Equipment.2006.25(12).-52-54.

[5] Tang Da-hai. Decoupling Control Strategy for Bus Self transfer with Two source Expansive Inner bridge Connection[J]. Automation of Electric Power Systems,2009.33(23).103-107.

[6] Tang Dahai , Yang Hemin ,Liu Chunjiang, et al.. Research on Inter bridge Connected Adaptive Backup Power Automatic Throw in [J]. Automation of Electric Power Systems,2009.33(15).108 -111

[7] LIU Hu-ping, Tang Da-hai, ZHENG Jian-yong, et al.. Self-adaptive automatic bus transfer scheme and its realization $[\mathbf{J}]$.Electric Power Automation Equipment,2005.25(8). 84-86

[8] Ruan Ai-min ,Li Min , Tang Da-hai. Application of Automatic Closing with Protective Blocking[J]. Jiangsu Electrical Engineering, 2003.22(4). $41-42$

[9] GB-14285-2006,Technical regulation of relay protection and safe automatic device $[\mathrm{S}]$.

[10] DL/T584-2007, Operating regulations of relay protection in $3 \sim 110 \mathrm{kV}$ electric network $[\mathrm{S}]$.

[11] DL/T 526-2013, General specification for automatic bus transfer equipment $[\mathrm{S}]$

[12] Tang Dahai. microcomputer control the automatic switching method for standby power [P]. National intellectual property office of the People's Republic of China, 2009.

[13] Tang Dahai. Bridge and single busbar connection method of microcomputer control automatic standby power input $[\mathrm{P}]$. The state intellectual property office of the People's Republic of China, 2011.[6].

[14] G. Eason, B. Noble, and I. N. Sneddon, "On certain integrals of Lipschitz-Hankel type involving products of Bessel functions," Phil. Trans. Roy. Soc. London, vol. A247, pp. 529-551, April 1955. (references)

[15] J. Clerk Maxwell, A Treatise on Electricity and Magnetism, 3rd ed., vol. 2. Oxford: Clarendon, 1892, pp.68-73.

[16] I. S. Jacobs and C. P. Bean, "Fine particles, thin films and exchange anisotropy," in Magnetism, vol. III, G. T. Rado and H. Suhl, Eds. New York: Academic, 1963, pp. 271-350.

[17] K. Elissa, "Title of paper if known," unpublished.

[18] R. Nicole, "Title of paper with only first word capitalized," J. Name Stand. Abbrev., in press.

[19] Y. Yorozu, M. Hirano, K. Oka, and Y. Tagawa, "Electron spectroscopy studies on magneto-optical media and plastic substrate interface," IEEE Transl. J. Magn. Japan, vol. 2, pp. 740-741, August 1987 [Digests 9th Annual Conf. Magnetics Japan, p. 301, 1982].

[20] M. Young, the Technical Writer's Handbook. Mill Valley, CA: University Science, 1989 